\title{
Thalassemia and Nephrolithiasis
}

\section{Beuy Joob ${ }^{1 *}$, Viroj Wiwanitkit ${ }^{2}$}

'Sanitation 1 Medical Academic Center, Bangkok Thailand

${ }^{2}$ Honorary professor, dr. DY Patil University, Pune, India

\section{Article Info}

\section{Article Notes}

Received: August 30, 2019

Accepted: September 11, 2019

\section{*Correspondence:}

Dr. Beuy Joob, Sanitation 1 Medical Academic Center Bangkok Thailand; Email: beuyjoob@hotmail.com.

${ }^{\circ} 2019$ Joob B. This article is distributed under the terms of the Creative Commons Attribution 4.0 International License.
Renal disorder is an important medical problem seen in any country. Basically, kidney plays important role in excretion and the impairment of kind can affect the general health of the patient. There are several causes of renal disorders. The relationship between renal disease and underlying genetic disorder is interesting. There are many genetic diseases that can present with renal problem. In addition, there are also many genetic diseases that can be the trigger factors for renal disease development. Here, the authors specifically discuss on an important comment genetic problem, thalassemia and its interrelationship with nephrolithiasis.

Generally, thalassemia is one of the most common genetic problem. The disease is due to inherited hemoglobin disorder that can result in anemic disease. The thalassemia patient will develop anemia and other additional pathologies such as bone abnormality. The kidney problem due to thalassemia is interesting. Nephrolithiasis is an important renal disorder detectable in patients with thalassemia. The thalassemia related hyperuricemia is believed to be an underlying cause of thalassemia related nephrolithiasis ${ }^{1,2}$. The problem is more common in thalassemia patient who receive splenectomy therapy ${ }^{3}$. The use of chelating therapy is also reported for relationship between thalassemia related nephrolithiasis ${ }^{4}$.

It is no doubt that thalassemia patient poses risk for nephrolithiasis. The monitoring of renal function among the thalassemia patient is necessary. Also, periodical check for renal stone should be done in caring of thalassemia patient.

\section{References}

1. Wong P, Fuller PJ, Gillespie MT, et al. Thalassemia bone disease: the association between nephrolithiasis, bone mineral density and fractures. Osteoporos Int. 2013 Jul; 24(7): 1965-71.

2. Chaloemwong J, Tantiworawit A, Rattanathammethee T, et al. Hyperuricemia, urine uric excretion, and associated complications in thalassemia patients. Ann Hematol. 2019 May; 98(5): 1101-1110.

3. Ammirabile M, Costantini S, Di Matola T, et al. Splenectomy is a risk factor for developing hyperuricemia and nephrolithiasis in patients with thalassemia intermedia: a retrospective study. Ricchi P, Blood Cells Mol Dis. 2012 Oct 15-Dec 15; 49(3-4): 133-5.

4. Ricchi P, Ammirabile M, Costantini S, et al. Nephrolithiasis in patients exposed to deferasirox and desferioxamine: probably an age-linked event with different effects on some renal parameters. Ann Hematol. 2014 Mar; 93(3): 525-7. 